\title{
Fractional-Order Oscillator Design Using Unity- Gain Voltage Buffers and OTAs
}

\author{
KARTCI, A.; HERENCSÁR, N.; KOTON, J.; BRANČÍK, L.; VRBA, K.
}

Circuits and Systems (MWSCAS), 2017 IEEE 60th International Midwest Symposium on

pp. 555-558

Electronic ISBN: 978-1-5090-6389-5

Electronic ISSN: 1558-3899

DOI: http://dx.doi.org/10.1109/MWSCAS.2017.8052983

Accepted manuscript

(C2017 IEEE. Personal use of this material is permitted. Permission from IEEE must be obtained for all other uses, in any current or future media, including reprinting/republishing this material for advertising or promotional purposes, creating new collective works, for resale or redistribution to servers or lists, or reuse of any copyrighted component of this work in other works. Aslihan Kartci; Norbert Herencsar; Jaroslav Koton; Lubomir Brancik; Kamil Vrba; Georgia Tsirimokou; Costas Psychalinos, "Fractional-Order Oscillator Design Using Unity-Gain Voltage Buffers and OTAs", Proceedings of the 2017 IEEE 60th International Midwest Symposium on Circuits and Systems (MWSCAS), pp. 555-558, 2017. DOI: 10.1109/MWSCAS.2017.8052983. Final version is available at http://ieeexplore.ieee.org/document/8052983/ 


\section{Fractional-Order Oscillator Design Using Unity-Gain Voltage Buffers and OTAs}

\author{
Aslihan Kartci ${ }^{1,2}$, Norbert Herencsar ${ }^{2}$, Jaroslav Koton ${ }^{2}$, \\ Lubomir Brancik ${ }^{1}$, Kamil Vrba ${ }^{2}$ \\ ${ }^{1}$ Dept. of Radio Electronics / ${ }^{2}$ Dept. of Telecommunications \\ Brno University of Technology \\ Technicka 3082/12, 61600 Brno, Czech Republic \\ \{kartci; herencsn; koton; brancik; vrbak\}@ feec.vutbr.cz
}

\author{
Georgia Tsirimokou, Costas Psychalinos \\ Physics Department, Electronics Laboratory \\ University of Patras \\ Rio Patras, GR-26504, Greece \\ tsirimg@upatras.gr; cpsychal@physics.upatras.gr
}

Abstract In this study, a new voltage-mode fractional-order oscillator using two unity-gain voltage buffers, two operational transconductance amplifiers, one resistor, and two capacitors is presented. The design procedure of integer-order as well as fractional-order oscillator employing in total $20 \mathrm{MOS}$ transistors is discussed. Effects of fractional-order capacitors on amplitude, phase, condition of oscillation, and frequency of oscillation are shown. Various case examples are given while SPICE simulations using TSMC $0.35 \mu \mathrm{m}$ level-3 CMOS process parameters with $\pm 1.65 \mathrm{~V}$ supply voltages verify their operation and compare with theor etical ones.

Keywords fractional-order circuit; fractional-order oscillator; flipped voltage follower; FVF; operational transconductance amplifier; OTA; voltage buffer; voltage-mode.

\section{INTRODUCTION}

Over the years several techniques for designing fractionalorder oscillators have been introduced [1], [2]. The implementation of such oscillators evidently requires the use of a fractional-order capacitor (FoC), which brings to researchers several design features such as possibility of changing the frequency of oscillation (FO) and condition of oscillation (CO), as will be demonstrated in this study. In open literature, the FoC is implemented using RC network, via active emulator, or by fabricated chemical chips [3]- [8]. As our comparative study given in Table I shows, the previous works in this area are mainly focused on fractional-order oscillator design derived from classical active elements-based structures such as opamps and with their equivalent macro models containing two or more energy storage elements [9]. Particularly, the studied quadrature or multiphase oscillators are the classic ones such as the Wien-bridge oscillator [10], Colpitts oscillator [1], and Hartley oscillator [11]. Their behavior was investigated theoretically and also experimentally. On the other hand, this study aims to present the new fractional-order oscillator using compact CMOS active building blocks (ABBs) with reduced transistor count and shows the effect of fractional-orders on FO, CO, phase, and amplitude. Although class-AB cells are nonlinear, they can be modified as linear circuits with different combinations [12]- [15]. Beside this, due to their characteristics such as low output impedance, low quiescent power consumption, low

This article is based upon work from COST Action CA15225, a network supported by COST (European Cooperation in Science and Technology). Research described in this paper was financed by the National Sustainability Program under grant LO1401 and by the Czech Science Foundation under grant no. 16-06175S. For the research, infrastructure of the SIX Center was used. voltage with large current sinking and high driving capability, they are more developed voltage followers compared to conventional ones. Some of them even have almost unity voltage gain on neglecting short-channel effects [15]. Therefore, they are mainly used in analogue and mixed-signal designs such as oscillators, filters, or communication applications. One of the most recently developed class-AB cell is the flipped voltage follower (FVF), which was introduced by Torralba et al. in 2002 [12]. This compact FVF is based on two complementary differential flipped voltage followers. Another high-performance ABB used in this study is the basic CMOS transconductor, which has a voltage to current (V-I) conversion capability and uses only two CMOS transistors and two control voltages [16], [17]. SPICE simulation results using TSMC $0.35 \mu \mathrm{m}$ level-3 CMOS process parameters and with $\pm 1.65 \mathrm{~V}$ supply voltages are given to verify the theoretical analysis based on using RC trees emulating the fractional operators $s^{\alpha}$. The paper is organized as follows: After this introductory part, used compact cells and integer- as well as fractional-order oscillator design procedure are briefly introduced. Section III presents the simulation results and the last two sections discussion of the results, concluding this study.

\section{CIRCUIT DESCRIPTION}

\section{A. Voltage Buffer Using Flipped Voltage Follower (FVF)}

The CMOS implementation of unity-gain voltage buffer based on class-AB flipped voltage follower, i.e. $V_{\text {out }}=V_{\text {in }}$, is shown in Fig. 1(a) [12]. As it is evident, it uses two complementary differential flipped voltage followers (DFVFs)

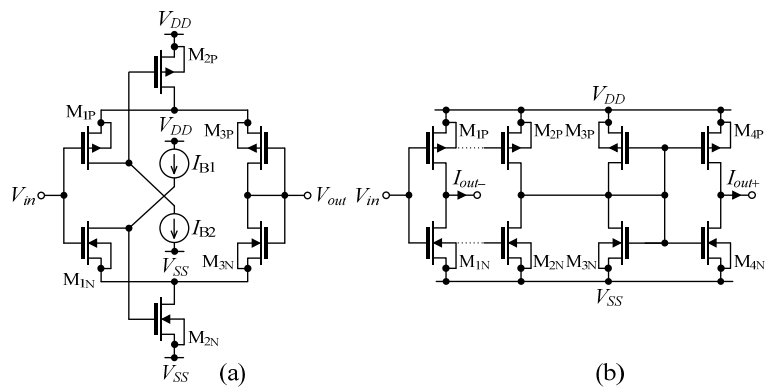

Fig. 1. CMOS implementation of active blocks: (a) voltage buffer, (b) transconductor. 
TABLE I. COMPARATIVE STUDY OF FRACTIONAL-ORDER OSCILLATORS.

\begin{tabular}{|c|c|c|c|c|c|}
\hline Ref. & $\begin{array}{c}\text { No. of } \\
\text { ABBs }\end{array}$ & $\begin{array}{c}\text { No. of } \\
\text { trans. }\end{array}$ & $\begin{array}{c}\text { No. of } \\
\text { R / C / L }\end{array}$ & Orders & $\begin{array}{c}\text { Power } \\
\text { supplies }\end{array}$ \\
\hline$[1]$ & - & 1 BJT & 1 gr. / 2 gr. / 1 fl. & - & - \\
\hline$[2]$ & 3 opamp & - & 9 fl. / 3 gr. / - & 1.5 & $\pm 15 \mathrm{~V}$ \\
\hline$[9]$ & 1 opamp & - & $3 \mathrm{fl} . ; 2$ gr. / 1 fl.; 1 gr. / & 1.8 & - \\
\hline$[10]$ & 1 opamp & - & 1 fl.; 1 gr. / 1 fl.; 1 gr. / & 1.7 & - \\
\hline$[11]$ & 1 opamp & - & 2 fl. / 1 gr. / 2 fl. & $2.6 ; 2.7$ & $\pm 2 \mathrm{~V}$ \\
\hline Our & - & 20 CMOS & $1 \mathrm{fl} . / 1$ fl.; 1 gr. / & $1 ; 1.5 ; 2$ & $\pm 1.65 \mathrm{~V}$ \\
\hline
\end{tabular}

$M_{1 P}-M_{3 P}$ and $M_{1 N}-M_{3 N}$ with quiescent currents $I_{B 1}$ and $\mathrm{I}_{\mathrm{B} 2}$, respectively. When the input voltage signal $\mathrm{V}_{\text {in }}$ increases with respect to the output voltage $\mathrm{V}_{\text {out }}$, then $\mathrm{V}_{\mathrm{SG}(\mathrm{M} 3 \mathrm{P})}$ increases while $\mathrm{V}_{\mathrm{GS}(\mathrm{M} 3 \mathrm{~N})}$ decreases. Similarly, current through $\mathrm{M}_{3 \mathrm{P}}$ increases and $\mathrm{M}_{3 \mathrm{~N}}$ decreases. This generates a positive output current that charges the load capacitance and increases the output voltage $V_{\text {out }}$ until it reaches a value $V_{\text {in }}$. This buffer operates in class $\mathrm{AB}$, resulting in transient currents of the output transistors much larger than their corresponding quiescent currents $\mathrm{I}_{\mathrm{B} 1}$ and $\mathrm{I}_{\mathrm{B} 2}$. Theoretically, the input and output impedance of this buffer are infinite and zero, respectively.

\section{B. Operational Transconductance Amplifier (OTA)}

The CMOS implementation of single-input differentialoutput transconductor is shown in Fig. 1(b). Assuming squarelaw behavior for the current-voltage relationship of the MOS transistors $\mathrm{M}_{1 \mathrm{P}}$ and $\mathrm{M}_{1 \mathrm{~N}}$ and ignoring channel-length modulation effect, their drain currents will be given as in [16], [17], and, thus, the current-voltage relationship of the transconductor can be approximated by the linear expression: $I_{\text {out- }}=-g_{m} V_{\text {in }}$, where $g_{m}=k_{N} V_{D D}$. This linear behavior is achieved under the assumptions: $\mathrm{k}_{\mathrm{P}} @ \mathrm{k}_{\mathrm{N}}$ and $\mathrm{V}_{\mathrm{SS}} @ \mathrm{~V}_{\mathrm{DD}}+\mathrm{V}_{\mathrm{th} \_\mathrm{N}}-\mathrm{IV}_{\mathrm{th} \_\mathrm{P}} \mathrm{I}$, where $\mathrm{V}_{\mathrm{th} \_\mathrm{N}}$ and $\mathrm{V}_{\text {th_P }}$ are the threshold voltages of the NMOS and PMOS transistors. In order to keep the transistors in saturation region, the constraints $V_{D 1}+V_{\text {th_N }} \quad V_{\text {in }} \quad V_{D 1}-\left|V_{\text {th_P }}\right|$ should be satisfied, where $V_{D 1}$ is the (common) drain voltage of transistors $M_{1 P}$ and $\mathrm{M}_{1 \mathrm{~N}}$, respectively.

Interconnecting the transconductor with unity-gain current follower (see $\mathrm{M}_{2 \mathrm{P}}-\mathrm{M}_{4 \mathrm{P}}$ and $\mathrm{M}_{2 \mathrm{~N}}-\mathrm{M}_{4 \mathrm{~N}}$ in Fig. 1(b) [18]) the current-voltage relationship of the transconductor can be characterized with the equation $\mathrm{I}_{\text {out }+}=\mathrm{g}_{\mathrm{m}} \mathrm{V}_{\text {in }}$.

\section{Integer-Order Oscillator Design}

The proposed voltage-mode oscillator with unity-gain voltage buffers based on flipped voltage followers, two transconductors, one resistor, and two capacitors is shown in Fig. 2. Assuming both capacitors are ideal with capacitance $C$ and used ABBs are also ideal, i.e. ignoring parasitic effects, the characteristic equation (CE) of this oscillator is as follows:

$$
\mathrm{CE}: \quad \mathrm{s}^{2} \mathrm{RC}_{1} \mathrm{C}_{2}+\mathrm{s}\left(\mathrm{g}_{\mathrm{m} 2} \mathrm{RC}_{1}-\mathrm{g}_{\mathrm{ml}} \mathrm{RC}_{2}\right)+\mathrm{g}_{\mathrm{m} 2}=0 \text {, }
$$

from which the $\mathrm{CO}$ and $\mathrm{FO}$ can be evaluated as:

$$
\mathrm{CO}: \quad \mathrm{C}_{2} \quad \frac{\mathrm{g}_{\mathrm{m} 2}}{\mathrm{~g}_{\mathrm{m} 1}} \mathrm{C}_{1}, \quad \mathrm{FO}: \omega_{0}=\sqrt{\frac{\mathrm{g}_{\mathrm{m} 2}}{\mathrm{C}_{1} \mathrm{C}_{2} \mathrm{R}}},
$$

therefore, the FO can be controlled by adjusting the value of the resistor $\mathrm{R}$ without affect of $\mathrm{CO}$.

\section{Fractional-Order Oscillator Design}

Replacing in the oscillator in Fig. 2 the ideal capacitors $\mathrm{C}_{\mathrm{i}}$, $\mathrm{i}=\{1,2\}$, by FoCs $\left(\mathrm{C}_{1} \Rightarrow \mathrm{C}_{\alpha}, \mathrm{C}_{2} \Rightarrow \mathrm{C}_{\beta}\right)$ with impedance ${ }_{\alpha}(\mathrm{s})=1 /\left(\mathrm{s}^{\alpha} \mathrm{C}_{\alpha}\right), \quad{ }_{\beta}(\mathrm{s})=1 /\left(\mathrm{s}^{\beta} \mathrm{C}_{\beta}\right)$, the fractional-order system can be described as:

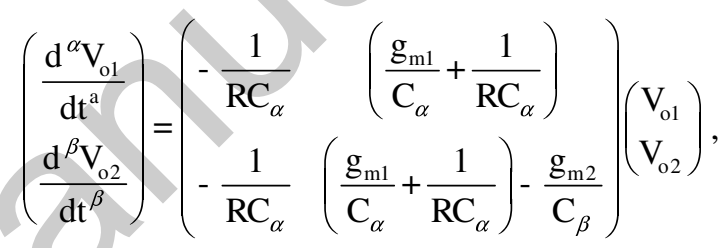

hence, the $\mathrm{CE}$ from (1) takes the following general form:

$$
\mathrm{CE}: \quad \mathrm{s}^{\alpha+\beta}-\mathrm{s}^{\beta} \frac{\mathrm{g}_{\mathrm{m} 1}}{\mathrm{C}_{\alpha}}+\mathrm{s}^{\alpha} \frac{\mathrm{g}_{\mathrm{m} 2}}{\mathrm{C}_{\beta}}+\frac{\mathrm{g}_{\mathrm{m} 2}}{\mathrm{C}_{\alpha} \mathrm{C}_{\beta} \mathrm{R}}=0 .
$$

By solving (5) the $\mathrm{CO}$ and FO of fractional-order oscillator can be obtained as:

$\mathrm{CO}$ :

$$
\begin{aligned}
& \mathrm{w}^{\alpha+\beta} \cos \frac{(\alpha+\beta) \mathrm{p}}{2}-\frac{\mathrm{g}_{\mathrm{m} 1}}{\mathrm{C}_{\alpha}} \mathrm{w}^{\beta} \cos \frac{\beta \mathrm{p}}{2}+\frac{\mathrm{g}_{\mathrm{m} 2}}{\mathrm{C}_{\beta}} \mathrm{w}^{\mathrm{a}} \cos \frac{\mathrm{a} \mathrm{p}}{2}+\frac{\mathrm{g}_{\mathrm{m} 2}}{\mathrm{RC}_{\alpha} \mathrm{C}_{\beta}}=0, \\
& \mathrm{FO}: \quad \mathrm{w}^{\alpha+\beta} \sin \frac{(\alpha+\beta) \mathrm{p}}{2}-\frac{\mathrm{g}_{\mathrm{m} 1}}{\mathrm{C}_{\alpha}} \mathrm{w}^{\beta} \sin \frac{\beta \mathrm{p}}{2}+\frac{\mathrm{g}_{\mathrm{m} 2}}{\mathrm{C}_{\beta}} \mathrm{w}^{\alpha} \sin \frac{\alpha \mathrm{p}}{2}=0 .
\end{aligned}
$$

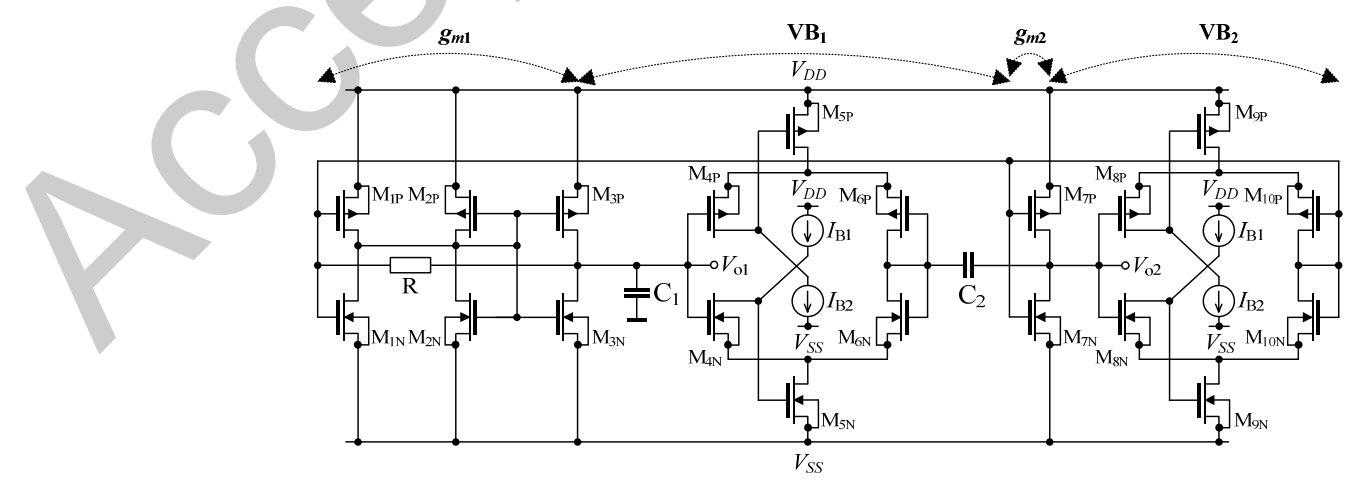

Fig. 2. Proposed voltage-mode oscillator. 
The phase difference $\phi$ between the two outputs $V_{o 1}$ and $\mathrm{V}_{\mathrm{o} 2}$ is calculated as:

$$
\mathrm{f}=\mathrm{f}_{\mathrm{o} 1}-\frac{\mathrm{p}\left[1-\operatorname{sign}\left(\mathrm{a}_{12}\right)\right]}{2}=\frac{\mathrm{p}\left[1-\operatorname{sign}\left(\mathrm{a}_{21}\right)\right]}{2}-\mathrm{f}_{\mathrm{o} 2},
$$

where

$$
\mathrm{f}_{\mathrm{o} 1}=\tan ^{-1} \frac{\mathrm{w}^{\alpha} \sin (0.5 \alpha \mathrm{p})}{\mathrm{w}^{\alpha} \cos (0.5 \alpha \mathrm{p})-\mathrm{a}_{11}}, \mathrm{f}_{\mathrm{o} 2}=\tan ^{-1} \frac{\mathrm{w}^{\beta} \sin (0.5 \beta \mathrm{p})}{\mathrm{w}^{\beta} \cos (0.5 \beta \mathrm{p})-\mathrm{a}_{22}} .
$$

\section{Simulation Results}

The behavior of voltage buffer, transconductor, and proposed voltage-mode integer- and fractional-order oscillators have been verified by SPICE simulations. In the design, transistors are modeled by the TSMC $0.35 \mu \mathrm{m}$ level-3 CMOS process parameters $\left(\mathrm{V}_{\text {th_N }}=0.545 \mathrm{~V}, \mathrm{~V}_{\text {th_P }}=-0.714 \mathrm{~V}\right.$, $\left.\mu_{\mathrm{N}}=436.26 \mathrm{~cm}^{2} /(\mathrm{V} \mathrm{s}), \mu_{\mathrm{P}}=212.23 \mathrm{~cm}^{2} /(\mathrm{V} \mathrm{s}), \mathrm{t}_{\mathrm{OX}}=7.9 \mathrm{~nm}\right)$. In simulations, the DC power supply voltages of given structures were set equal to $+\mathrm{V}_{\mathrm{DD}}=-\mathrm{V}_{\mathrm{SS}}=1.65 \mathrm{~V}$ and the aspect ratios of MOS transistors were $15 \mu \mathrm{m} / 0.5 \mu \mathrm{m}$ and $5 \mu \mathrm{m} / 0.5 \mu \mathrm{m}$ for all PMOS and NMOS, respectively. The bias currents in voltage buffers were set $\mathrm{I}_{\mathrm{B} 1}=\mathrm{I}_{\mathrm{B} 2}=250 \mathrm{~mA}$, which results in $\mathrm{DC}$ voltage gain 0.957 with $\mathrm{f}_{3 \mathrm{~dB}}$ frequency of 1.644 GHz. Similarly, the transconductance gains $\mathrm{g}_{\mathrm{m} 1}$ $\left(\mathrm{I}_{\text {out }+} / \mathrm{V}_{\text {in }}\right)$ and $\mathrm{g}_{\mathrm{m} 2}\left(\mathrm{I}_{\mathrm{out}-} / \mathrm{V}_{\text {in }}\right)$ are computed as $1.639 \mathrm{~mA} / \mathrm{V}$ and $1.778 \mathrm{~mA} / \mathrm{V}$, respectively, and their $\mathrm{f}_{3 \mathrm{~dB}}$ frequency is found to be $3.83 \mathrm{GHz}$ and $47.63 \mathrm{GHz}$. Hence, the maximum operating frequency of transconductors are $\mathrm{f}_{\max }=\min \left\{\mathrm{f}_{\mathrm{gm} 1}\right.$, $\left.\mathrm{f}_{\mathrm{gm} 2}\right\} \quad 3.83 \mathrm{GHz}$.

As a first step, the performance of the proposed integerorder oscillator $(\alpha=\beta=1)$ was evaluated. In this case, both capacitances have been chosen as: $\mathrm{C}_{1}=55 \mathrm{nF}, \mathrm{C}_{2}=100 \mathrm{nF}$, while the resistor was: $\mathrm{R}=1 \mathrm{k} \Omega$; according to (3), the theoretical value of the oscillation frequency was $\mathrm{f}_{0}=2.86 \mathrm{kHz}$. Figure 4(a) shows the simulated output waveforms with frequency of oscillation $1.63 \mathrm{kHz}$.

As a second step, the fractional-order oscillator with an order of $\mathrm{s}^{1.5}$ has been implemented. For this purpose, the capacitors of the integer-order oscillator in Fig. 2 were replaced with their fractional-order equivalents which were realized using the second-order RC tree shown in Fig. 3. Note that the values of $\mathrm{g}_{\mathrm{m} 1,2}$ have been kept the same with the previous case. Considering that $\alpha=0.9$ and $\beta=0.6$, their equivalent pseudo-capacitance values will be as follows: $\mathrm{C}_{\alpha} \approx 136.3 \mathrm{nF} \mathrm{s}^{-0.1} \quad\left(\mathrm{C}_{1}=55 \mathrm{nF} @ \mathrm{f}_{\mathrm{o}}\right)$ and $\mathrm{C}_{\beta} \approx 3.78 \mathrm{mF} \mathrm{s}^{-0.4}$ $\left(\mathrm{C}_{2}=100 \mathrm{nF} @ \mathrm{f}_{\mathrm{o}}\right)$. Also, the resistor $\mathrm{R}$ will equal to $1.64 \mathrm{k} \Omega$. Computed component values are given in Table II. During simulations, in order to start up the oscillations, the resistor was set $3.4 \mathrm{k} \Omega$ and the obtained $F O$ was $\mathrm{f}_{0}=0.741 \mathrm{kHz}$. The simulated output waveforms are shown in Fig. 4(b).

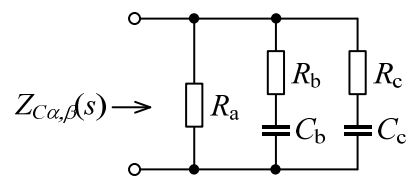

Fig. 3. RC tree realization of FoC.
TABLE II. COMPONENT VALUES USED IN SPICE SIMULATIONS FOR $\mathrm{C}_{\alpha}=55 \mathrm{nF} \cdot \mathrm{s}^{\alpha-1}, \mathrm{C}_{\beta}=100 \mathrm{nF} \cdot \mathrm{s}^{\beta-1}$.

\begin{tabular}{|l|l|l|l|l|}
\hline Variables Orders & $\boldsymbol{\alpha}=0.5$ & $\boldsymbol{\beta}=0.5$ & $\boldsymbol{\alpha}=0.9$ & $\boldsymbol{\beta}=0.6$ \\
\hline $\mathrm{R}_{\mathrm{a}}[\mathrm{k} \Omega]$ & 10.6 & 5.9 & 98.6 & 8.04 \\
\hline $\mathrm{R}_{\mathrm{b}}[\Omega]$ & 508 & 279.4 & 39.5 & 161.3 \\
\hline $\mathrm{C}_{\mathrm{b}}[\mathrm{nF}]$ & 24.3 & 44.2 & 48 & 54.1 \\
\hline $\mathrm{R}_{\mathrm{c}}[\mathrm{k} \Omega]$ & 3.5 & 1.9 & 85.6 & 1.9 \\
\hline $\mathrm{C}_{\mathrm{c}}[\mathrm{nF}]$ & 6.4 & 115.8 & 14.4 & 97.3 \\
\hline
\end{tabular}
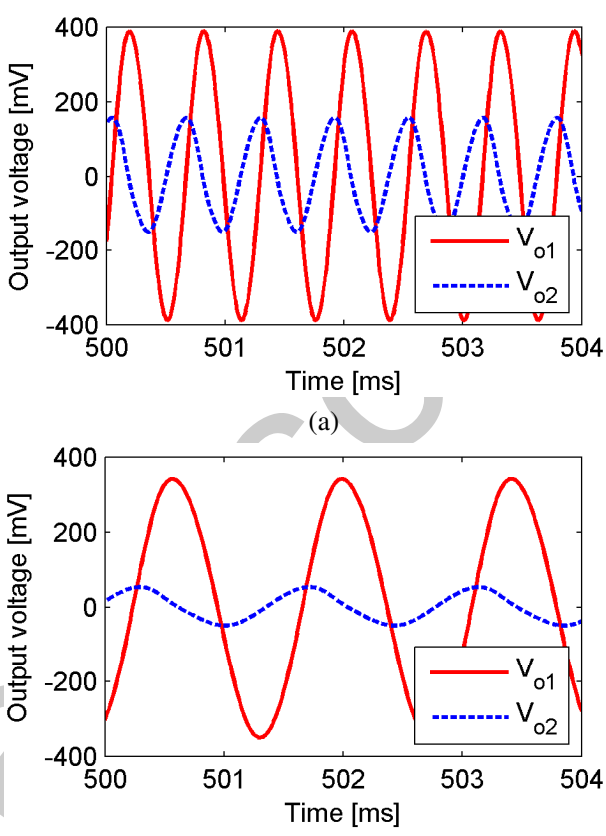

(b)

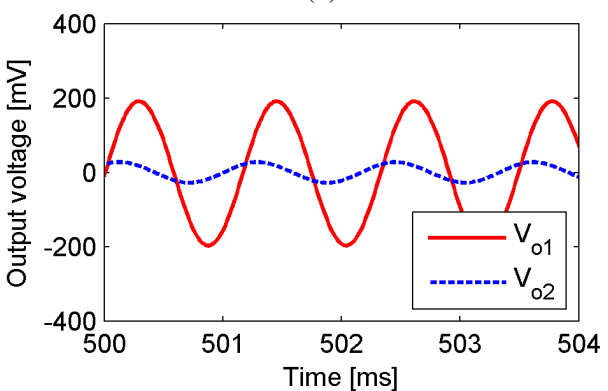

(c)

Fig. 4. Simulated output waveforms of the proposed voltage-mode oscillator: (a) $\alpha=\beta=1$, (b) $\alpha=0.9, \beta=0.6$, (c) $\alpha=\beta=0.5$.

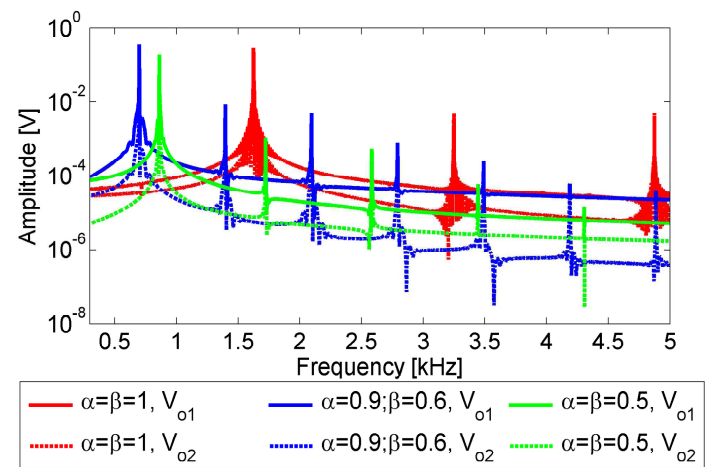

Fig. 5. Simulated frequency spectrum of outputs. 


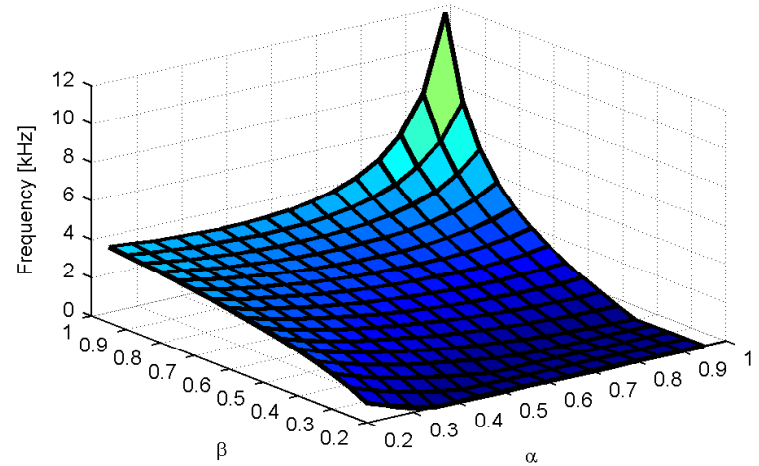

Fig. 6. Effect of fractional-orders $\alpha$ and $\beta$ on frequency of oscillation.

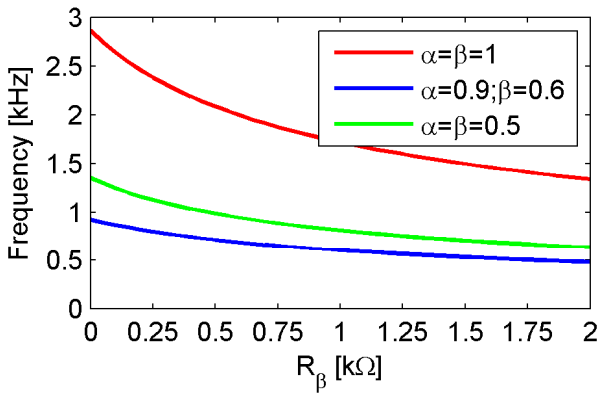

Fig. 7. Effect of parasitic resistance $\mathrm{R}_{\beta}$ on frequency of oscillation.

As a last step, a fractional-order oscillator with $\alpha+\beta=1$ has been investigated. Here, considering again the same values of $\mathrm{g}_{\mathrm{m} 1,2}$, the computed pseudo-capacitances for $\alpha=\beta=0.5$ were $\mathrm{C}_{\alpha} \approx 5.1 \mathrm{mF} \mathrm{s}^{-0.5}\left(\mathrm{C}_{1}=55 \mathrm{nF} @ \mathrm{f}_{\mathrm{o}}\right)$ and $\mathrm{C}_{\beta} \approx 9.2 \mathrm{mF} \mathrm{s}^{-0.5}$ $\left(\mathrm{C}_{2}=100 \mathrm{nF} @ \mathrm{f}_{\mathrm{o}}\right)$, which after substituting in (6a) the resulting condition of oscillation was $\mathrm{R}=4.48 \mathrm{k} \Omega$. Computed component values used in SPICE simulations are also given in Table II. Figure 4(c) shows the output responses and simulated FO is equal to $\mathrm{f}_{0}=0.861 \mathrm{kHz}$. In addition, the simulated frequency spectrum of outputs for each case is given in Fig. 5. The total power dissipation of the oscillator in all three cases is found to be $11.5 \mathrm{~mW}$.

\section{DISCUSSION ON RESULTS}

The output waveforms of the two state variables $V_{01}$ and $\mathrm{V}_{\mathrm{o} 2}$ under three different conditions of $\alpha$ and $\beta$ are shown. It can be noticed that the amplitude of the output waveforms are decreases while the order of oscillator is also decreasing. As it was shown, the FO can be changed by varying the fractionalorder $\alpha$ and/or $\beta$ without changing the capacitor values $\mathrm{C}_{\mathrm{i}}$. In particular, $\omega_{\alpha}=\left(\omega_{0}\right)^{1 / \alpha}$ for $\alpha<1$ and $\omega_{\beta}=\left(\omega_{0}\right)^{1 / \beta}$ for $\beta<1$, it is clear that extension of FOs are possible, which is demonstrated in Fig. 6. As it is evident from the obtained SPICE simulation results, there is a slight deviation in simulated FOs compared to theory. For an instance, considering a non-zero parasitic resistance $\mathrm{R}_{\beta}$ at output terminal of the first voltage buffer, which appears in series with capacitor $\mathrm{C}_{2}$ (integer-order case), i.e. ${ }_{2}(\mathrm{~s})=\mathrm{R}_{\beta}+1 / \mathrm{sC}_{2}$, the non-ideal FO in (3) becomes $\omega_{0}=\left[g_{m 2} /\left\{C_{1} C_{2} R\left(g_{m 2} R_{\beta}+1\right)\right\}\right]^{0.5}$. Similarly, FOs of both fractional-order cases are also affected by $\mathrm{R}_{\beta}$, which is shown in Fig. 7.

\section{CONCLUSION}

This paper demonstrates that a fractional-order oscillator with two different pseudo-capacitances can still sustain sinusoidal oscillations. In addition, it was shown that the condition and the frequency of oscillations are functions of the fractional-order. Clear advantage of the proposed compact fractional-order oscillator, compared to opamp-based counterparts presented in [1], [2], [10], and [11], is its simplicity, owing to the fact that employs only $20 \mathrm{MOS}$ transistors.

\section{REFERENCES}

[1] A.G. Radwan, A.S. Elwakil, A.M. Soliman, "Fractional-order sinusoidal oscillators: design procedure and practical examples," IEEE Trans. on Circuits and Systems I: Regular Papers, vol. 55, pp. 2051-2063, 2008.

[2] B. Maundy, A. Elwakil, S. Gift, "On the realization of multiphase oscillators using fractional-order allpass filters," Circuits, Systems, and Signal Processing, vol. 31, pp. 3-17, 2012.

[3] M. Nakagawa, K. Sorimachi, "Basic characteristics of a fractance device," IEICE Trans. on Fundamentals of Electronics, Communications and Computer Sciences, vol. 75, pp. 1814-1819, 1992.

[4] I. Dimeas, G. Tsirimokou, C. Psychalinos, A. Elwakil, "Realization of fractional-order capacitor and inductor emulators using current feedback operational amplifiers," In Proc. of Int. Symp. on Nonlinear Theory and its Applications (NOLTA), Hong Kong, China, 2015, pp. 237-240.

[5] G. Tsirimokou, C. Psychalinos, T.J. Freeborn, A.S. Elwakil, "Emulation of current excited fractional-order capacitors and inductors using OTA topologies," Microelectronics Journal, vol. 55, pp. 70-81, 2016.

[6] G. Tsirimokou, C. Psychalinos, A.S. Elwakil, K.N. Salama, "Electronically tunable fully integrated fractional-order resonator," IEEE Trans. on Circuits and Systems II, in press, 2017.

[7] A.M. Elshurafa, M.N. Almadhoun, K.N. Salama, H.N. Alshareef, "Microscale electrostatic fractional capacitors using reduced graphene oxide percolated polymer composites," Applied Physics Letters, vol. 102, pp. 232901-1-232901-4, 2013.

[8] P. Ushakov, A. Shadrin, D. Kubanek, J. Koton, "Passive fractional-order components based on resistive-capacitive circuits with distributed parameters," in Proc. of 39th TSP, Vienna, Austria, 2016, pp. 638-642.

[9] L.A. Said, A.G. Radwan, A.H. Madian, A.M. Soliman, "Two-port two impedances fractional order oscillators," Microelectronics Journal, vol. 55, pp. 40-52, 2016.

[10] W. Ahmad, R. El-Khazali, A.S Elwakil, "Fractional-order Wien-bridge oscillator," Electronics Letters, vol. 37, pp. 1110-1112, 2001.

[11] A.S. Elwakil, A. Agambayev, A. Allagui, K.N. Salama, "Experimental demonstration of fractional-order oscillators of orders 2.6 and 2.7," Chaos, Solitons \& Fractals, vol. 96, pp. 160-164, 2017.

[12] A. Torralba, R.G. Carvajal, J. Galan, J. Ramirez-Angulo, "Compact low power high slew rate CMOS buffer for large capacitive loads," Electronics Letters, vol. 38, pp. 1348-1349, 2002.

[13] R.G. Carvajal, J. Ramírez-Angulo, A.J. López-Martín, A. Torralba, J.A.G. Galán, A. Carlosena, F.M. Chavero, "The flipped voltage follower: A useful cell for low-voltage low-power circuit design," IEEE Trans. on Circuits and Systems I, vol. 52, pp. 1276-1291, 2005.

[14] A.S. Sedra, K.C. Smith, Microelectronics circuits, (5th ed.), New York Oxford University Press, 2005.

[15] C. Cakir, S. Minaei, O. Cicekoglu, "Low voltage low power CMOS current differencing buffered amplifier," Analog Integrated Circuits and Signal Processing, vol. 62, pp. 237-244, 2010.

[16] B. Nauta, "A CMOS transconductance-C filter technique for very high frequencies,” IEEE J. Solid-State Circuits, vol. 27, pp. 142-153, 1992.

[17] N. Herencsar, J. Koton, K. Vrba, O. Cicekoglu, "Low-voltage fully cascadable resistorless transadmittance-mode all-pass filter," in Proc. of 57th IEEE MWSCAS, College Station, USA, 2014, pp. 185-188.

[18] E.I. El-Masry, J.W. Gates, "A novel continuous-time current-mode differentiator and its applications," IEEE Trans. on Circuits and Systems II, vol. 43, no. 1, pp. 56- 59, 1996. 